\title{
Power Factor Correction Dual Input SEPIC Converter based Single Phase Induction Motor Drive with Speed Control
}

\author{
Jethose VIJAYAKUMAR ${ }^{1 *}$, Manoharan SUBRAMANIAN ${ }^{2}$ \\ ${ }^{1}$ JCT College of Engineering and Technology, Coimbatore, 641105, Tamil Nadu, India \\ vjithosh@gmail.com (*Corresponding author) \\ ${ }^{2}$ Karpagam College of Engineering, Coimbatore, 641032, Tamil Nadu, India \\ Manoish07@gmail.com
}

\begin{abstract}
This paper presents power factor correction (PFC) of single-phase induction motor (SPIM) using reconversion dual input single-ended primary inductor converter (DIPSEPIC) with Fuzzy indirect field-oriented control of speed. This work deals with an alternative approach to improving the power factor and the efficiency of a single-phase induction motor utilizing induced electromotive force (EMF) in the open auxiliary winding, which is unutilized during running conditions in a conventional SPIM. The auxiliary winding power can be varied in order to achieve control over the phase angle and current. A closed-loop control scheme with PFC reconversion DIPSEPIC is proposed. The design and development of the novel PFC reconversion DIPSEPIC converter is presented. The assorted parameters are executed, and the simulation responses of the model under diverse conditions are determined. The unified approach is virtually acquired using MATLAB Simulink model, and the same has been implemented in real-time by employing the TMS320F240 digital signal processor platform. The performance of the proposed drive is correlated with that of the simulation model. The implementation of the suggested framework has shown an improvement of the power factor and of the efficiency of the motor. Moreover, the speed control of single-phase induction motor using the Fuzzy indirect field-oriented control (IFOC) had increased stability to sudden speed changes and load torque distortions.
\end{abstract}

Keywords: Dual Input SEPIC, Indirect Field Oriented Control, Power factor correction, Single-phase induction motor.

\section{Introduction}

Most industrial processing facilities utilize a very high number of induction motors to operate their pumps, conveyors, and other machinery in the plants. These induction motors operate under low power factor in most of the industrial utilities. Many industries are charged with a penalty for a lower power factor (usually under 0.80 or 0.85 ), (Mishra et al., 2016). By adding power factor correction, one can get rid of the power factor penalty. Many electric utilities charge based on the highest registered demand either in kilowatts (kW meter), or percentage of kVA (kVA meter). Due to this low power factor, the percentage of measured $\mathrm{kVA}$ is higher than that of the $\mathrm{kW}$ demand. Therefore, improving the power factor through power factor correction will reduce the demand charge, which can contribute to reducing consumer's electricity bill.

Power factor correction can be exceedingly beneficial. Benefits comprise everything from reduced demand charges on the power system to the increased load carrying capabilities in the existing circuits and overall reduced power system losses. The PFC design is based on the fact that under less than full load conditions, the field windings of an induction motor will go forward to draw a nearly full load current level even though it is unnecessary to handle the reduced load. As a consequence, the electrical load of the motor becomes more reactive; thereby reducing the power factor. In this state of affairs, a more significant percentage of the motor power is converted into heat instead of useful output torque. The PFC compensates for this condition by sensing the phase lag of the current and reducing the potential applied to the motor while increasing phase lag.

The remainder of this paper is as follows. Section 1 presents the need for power factor correction in induction motors and proposes an alternative method for improving power factor in SPIM. Closed-loop architecture is presented and the operation of the PFC reconversion DIPSEPIC converter is explained. Section 2 sets forth the design of DIPSPEIC converter components in detail. Section 3 provides simulation test results and analysis of SPIM with PFC reconversion DIPSEPIC under the steady-state and transient state. Section 4 presents the hardware experimental test setup execution and its output. Section 5 discusses the results obtained and presents a comparative analysis of the results achieved. Section 6 presents the conclusion of this paper, namely that the proposed technique has shown 
significant improvement concerning the SPIM power factor, motor efficiency, and overall system power factor and functional efficiency.

\section{Proposed Method}

This work deals with an alternative approach to improving the power factor and the efficiency of a single phase induction motor (SPIM) without changing its design parameters. A single-phase capacitor-start motor utilizes a starting capacitor for generating the starting torque. The starting winding gets disconnected by the centrifugal switch as the rotor speed reaches $75 \%$ of the synchronous speed of the motor. Under running conditions, the rotor rotates in the magnetic field set up by both main winding and auxiliary winding. The main winding magnetic flux linkage contributes to the effective running of the motor, but the flux linkage due to auxiliary winding does not add to the energy conversion. The physical presence of the open auxiliary winding in the motor will induce electromotive force (EMF) to the open auxiliary winding and the magnitude of induced EMF depends upon the turns ratio of auxiliary winding to the main winding (Muteba \& Nicolae, 2017). The voltage induced within the auxiliary winding is unutilized. This paper presents the design and implementation of a SPIM drive with a view to improving the power factor by utilizing induced electromotive force (EMF) in the open auxiliary winding, which is unutilized in a conventional SPIM.

\section{Feasibility Study}

The following research works substantiate the feasibility of utilizing auxiliary winding power with a closed-loop control scheme. Da Silva et al. (2010) showed that the mean value of real input power of a capacitor-run single-phase induction motor can be obtained by

$\mathrm{P} 1 \mathrm{ph}=1 \frac{1}{T} \int_{t}^{t+T}\left(V_{T} \mathrm{x}\left(\mathrm{I}_{\text {main }}+\mathrm{I}_{\text {aux }}\right)\right) \mathrm{dt}$

where $V_{T}, \mathrm{I}_{\text {main }}$ and $\mathrm{I}_{\text {aux }}$ are applied voltage, the current of main winding and the current of auxiliary winding, taken for one period of the time, respectively. Collins et al. (1988) stated that, with the main winding directly connected to the utility supply, control over its current was lost. However, if the auxiliary winding is connected to a variable voltage and a variable-phase power supply, control over the phase angle, and the current is possible. In order to control them, the relationship between this angle and the auxiliary winding voltage phase angle must be determined. Tamrakar \& Malik (1999) proposed a closedloop plan in which the reactive power in the main winding is sensed and compared with the desired reactive power. The error signal obtained is utilized in order to operate the controller so as to obtain the desired power factor. Zhao et al. (2017) showed the feasibility of using induced auxiliary winding voltage for energy recycling. They proposed a new hybrid excitation motor in which auxiliary winding was introduced artificially into a parallel hybrid excitation machine with a synchronous stator. Peuteman \& Van Heerswynghels (2010) exhibited that, active power is transferred from the auxiliary winding to the main winding and injected back into the grid. Since the auxiliary winding consumes more active power than the power injected into the grid by the main winding, the total active power consumption of the motor remains positive.

Power factor correction techniques can be considered to be of two specific types - passive and active passive power factor correction techniques being the best option for low power, cost-sensitive applications. The dynamic power factor correction techniques are applied in most of the practical applications due to their outstanding performance (Radha Munuswamy et al., 2019).

\section{Quantitative Methods}

In this paper, the practical application of PFC reconversion DIPSEPIC-fed single-phase induction motor drive utilizing Fuzzy indirect field-oriented control (IFOC) is presented. The speed control is achieved by Fuzzy IFOC but the detailed design is not presented in this paper as it deviates from the considerable primary scope of this paper. This framework encompasses PFC DIPSEPIC, voltage source inverter (VSI), SPIM, IFOC with average current control and auxiliary current control. Average current follows sinusoidal line voltage by extracting the average current information from the auxiliary winding (Kim et al., 2017). The proposed control scheme offers three independent controls: average current-mode control for PFC correction Indirect field-oriented control for speed control of induction motor (Jannati et al., 2017). Auxiliary regenerative current control (Sessa et al., 2014); (Mehta \& Balamurugan, 2016) for improving the performance of SPIM. 
Architecture of SPIM Drive Using PFC Reconversion DIPSEPIC Converter

To achieve closed-loop control of SPIM with PFC reconversion DIPSEPIC, the following parameters are sensed, (Figure 1) namely: the auxiliary winding voltage $V_{A u x}$, auxiliary winding current $I_{A u x}$, boost converter current $I_{S A}$, SPIM torque $T_{e}$ and SPIM speed $\omega_{r}$. The control arrangement comprises a current-control loop, power-control loop, the input voltage feed-forward block, and the phase controlling logic. In the outer control loop, the actual auxiliary winding power $P_{A u x}$ is compared with the desired reference power. The control error is executed by the PI (ProportionalIntegral) controller, which produces the amplitude of the current $I_{P}$. The necessary magnitude $\left(I_{P}\right)$ is multiplied by the reference sine wave $\left(V_{A u x}\right)$, which is derived from the shape of the auxiliary winding voltage. The current controller makes the inverter output current sinusoidal and in-phase with the voltage to achieve unity power factor (Senthil Kumar et al., 2015). When obtaining the reference sine wave from the auxiliary winding voltage, voltage feed-forward block $\left|V_{A u x}\right|$ is added to avoid variation in the input voltage. This block consists of a low-pass filter, which calculates the average value of the auxiliary winding voltage. This average value is recalculated to the root mean square (RMS) value to maintain a sinusoidal shape, and it is utilized for reactive power compensation.

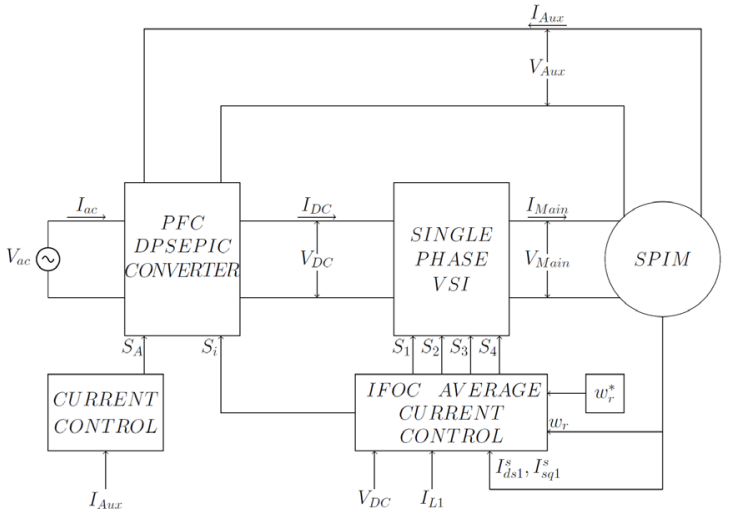

Figure 1. Architecture of SPIM Drive Using PFC Reconversion DIPSEPIC Converter

The reference current is compared with the actual current sensed on the auxiliary winding, and the difference is processed by the PI controllers (Errouissi et al., 2018); (Gnanavadivel et al., 2019). The output from this controller consists in the duty cycles of the pulse width modulation
(PWM) signals for the auxiliary converters. The input current is controlled in order to achieve the desired value of auxiliary winding power on the DC-bus. The outer power loop keeps the auxiliary winding power at the required level. The bandwidth of the voltage-control loop is set below $20 \mathrm{~Hz}$ to eliminate the second harmonic in the DC bus voltage.

Where reference power is $65 \%$ of the SPIM, output power $\mathrm{P}_{\text {Aux }}^{*}$ is given as,

$\mathrm{P}_{\text {Aux }}^{*}=\frac{2 \pi T_{e} \omega_{r}}{60} * 0.65$

Where actual auxiliary winding power $P_{A u x}$ is given as,

$\mathrm{P}_{\text {Aux }}=V_{A u x} * I_{A u x}$

So at nth sampling time, the error power $P_{\text {ERROR }}(\mathrm{n})$ is given as,

$\mathrm{P}_{\text {ERROR }}(\mathrm{n})=\mathrm{P}_{\text {AUx }}^{*}(\mathrm{n})-\mathrm{P}_{\text {AUx }}(\mathrm{n}-1)$

This error power is given to PI Power controller to generate output amplitude of the reference current $I_{P}$ and it can be expressed as,

$\left.\mathrm{I}_{\mathrm{p}}(\mathrm{n})=\mathrm{I}_{\mathrm{p}}(\mathrm{n}-1)+\mathrm{k}_{\mathrm{pp}}\left(\mathrm{P}_{\text {ERROR }} \mathrm{n}\right)-\mathrm{P}_{\text {ЕRROR }}(\mathrm{n}-1)\right)+\mathrm{k}_{\mathrm{Pi}} \mathrm{P}_{\text {ERROR }}(\mathrm{n})$

Where $\mathrm{k}_{\mathrm{p}_{\mathrm{p}}}$ is the proportional gain and $\mathrm{k}_{\mathrm{Pi}}$ is the integral gain of the PI power controller.

For the input current shaping as sinusoidal current the switching current $I_{\mathrm{SA}}$ is compared with the reference current $I_{\mathrm{SA}}^{*}$. The reference current is obtained as

$\mathrm{I}_{\mathrm{SA}}^{*}=\mathrm{i}_{\mathrm{p}}(\mathrm{n}) * \mathrm{u}(\mathrm{t})$

$\mathrm{u}(\mathrm{t})=\left|V_{\text {Aux }}\right| / \mathrm{V}_{\text {Aux }}$

The reference current $I_{\mathrm{SA}}^{*}$ is compared with the switching current $\mathrm{I}_{\mathrm{SA}}$ which results in inductor current error and it is given as

$\mathrm{I}_{\mathrm{SA}(\text { error) }}=\mathrm{I}_{\mathrm{SA}}^{*}-\mathrm{I}_{\mathrm{SA}}$

This error current is fed to PI current controller. PI current controller provides output duty cycles $\mathrm{D}_{\mathrm{A}}$ and it is given by

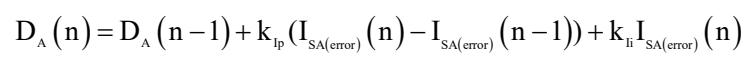

Where $\mathrm{k}_{\mathrm{Ip}}$ is the proportional gain and $\mathrm{k}_{\mathrm{Ii}}$ is the integral gain of the PI current controller. 
This duty cycle $\mathrm{D}_{\mathrm{A}}$ is compared with a sawtooth carrier signal of $10 \mathrm{kHz}$. The logic of generating PWM pulses for MOSFET switching can be expressed as, If $\mathrm{D}_{\mathrm{A}}>$ Carrier Signal, then metal oxide semiconductor field effect transistor (MOSFET) is ON else it is OFF.

\section{PFC Reconversion DIPSEPIC Converter}

The equivalent circuit diagram of the PFC reconversion DIPSEPIC converter is shown in Figure 2.

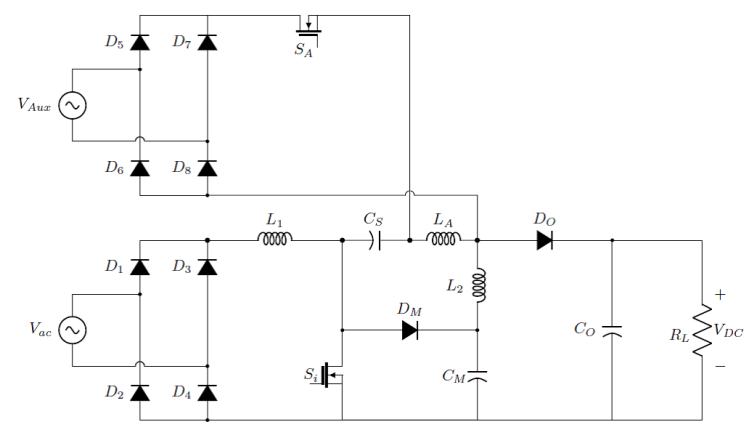

Figure 2. Circuit Diagram of PFC Reconversion DIPSEPIC Converter

This converter has an individual framework comprising an inductor $\left(L_{1}, L_{2} \& L_{A}\right)$, power switches $\left(S_{1}-S_{4}, S_{A}, S_{i}\right)$, power diodes $\left(D_{M}, D_{A}, D_{o}\right)$, capacitors $\left(C_{S}, C_{M}, C_{o}\right)$, and SPIM.

In this operation, two input power sources $V_{a c}$ and $V_{A u x}$ (Auxiliary Winding of SPIM) are responsible for supplying the $V_{D C}$ (DC-Link). The switches, $S_{i}$ and $S_{A}$ have a specific duty to perform. Here, $S_{i}$ is active so as to regulate DC-Link voltage to desired value by controlling inductor current $L_{A}$ of DIPSEPIC converter. In addition, reconversion of auxiliary winding power fed to DC-link is achieved by the boost converter. Regulating the boost converter current to desired value is achieved by controlling the switch $S_{A}$. In view of the switching states, there are four different operating modes in one switching period.

Switching State $1\left[t_{0}, t_{1}\right]$ :

In this mode, switch $S_{A}$ is $\mathrm{ON}$ and switch $S_{i}$ is OFF. When $S_{A}$ is ON, Diode $D_{A}$ is reverse biased. The auxiliary winding $V_{A u x}$ charges the inductor $L_{A}$ and increases the inductor current. $S_{i}$ is OFF, Diode $D_{0}$ is $\mathrm{ON}$, the energy stored in the input inductor $L_{1}$ and capacitor $C_{S}$ charges the output capacitor $C_{o}$. At this instant, the energy stored in the inductor $L_{2}$ charges the output capacitor
$C_{O}$. Diode $D_{m}$ is $\mathrm{ON}$, hence the energy stored in the input inductor $L_{1}$ charges the capacitor $C_{M}$. Simultaneously, the capacitor $C_{o}$ discharges and delivers the stored energy to the load. Equivalent circuit of PFC reconversion DIPSEPIC converter in this state is shown in Figure 3(a).

Switching State $2\left[t_{1}, t_{2}\right]$ :

In this mode, switch $S_{A}$ is turned OFF and switch $S_{i}$ is still OFF. When $S_{A}$ is OFF, diode $D_{A}$ is ON, hence the auxiliary winding voltage $V_{A u x}$ charges the capacitor $C_{O}$ and energy stored in inductor $L_{A}$ also charges the capacitor $C_{o}$.

When $S_{i}$ is OFF, Diode $D_{0}$ is ON, hence the energy stored in the input inductor $L_{1}$ and capacitor $C_{S}$ charges the output capacitor $C_{o}$. At this instant, the energy stored in the inductor $L_{2}$ also charges the output capacitor $C_{O}$.

When diode $D_{m}$ is $\mathrm{ON}$, the energy stored in the input inductor $L_{1}$ charges the capacitor $C_{M}$. Simultaneously, capacitor $C_{o}$ discharges and delivers the stored energy to load. Equivalent circuit of PFC reconversion DIPSEPIC converter in this state is shown in Figure 3(b).

Switching State $3\left[t_{2}, t_{3}\right]$ :

In this mode, switch $S_{A}$ is OFF and switch $S_{i}$ is ON. When $S_{A}$ is OFF, diode $D_{A}$ is ON, hence the auxiliary winding voltage $V_{A u x}$ charges the capacitor $C_{O}$ and inductor $L_{A}$ stored energy also charges the capacitor $C_{o}$.

When $S_{i}$ is ON, diodes $D_{0}$ and $D_{M}$ are in reversed biased condition. So the AC input $V_{a c}$ charges the inductor $L_{1}$ and increases the inductor current to charge the capacitor $C_{M}$, inductor $L_{2}$, and capacitor $C_{M}$. As a result, it increases the inductor current and capacitor voltage respectively. Simultaneously the capacitor $C_{o}$ discharges and delivers the stored energy to load. Equivalent circuit of PFC reconversion DIPSEPIC converter in this state is shown in Figure 3(c).

Switching State $4\left[t_{3}, t_{4}\right]$ :

In this mode, switch $S_{A}$ is $\mathrm{ON}$ and switch $S_{i}$ is ON. When $S_{A}$ is ON, diode $D_{A}$ is reverse biased. So the auxiliary winding voltage $V_{A u x}$ charges the inductor $L_{A}$ and increases the inductor current.

When $S_{i}$ is ON, diodes $D_{0}$ and $D_{M}$ are in reversed biased condition. The AC input $V_{a c}$ charges the inductor $L_{l}$ to increase the inductor current and the 


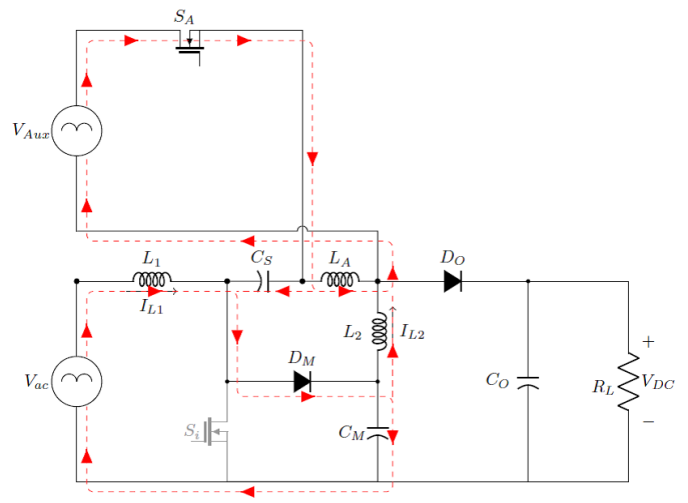

(a) Switching State $1\left[\mathrm{t}_{0}, \mathrm{t}_{1}\right]$

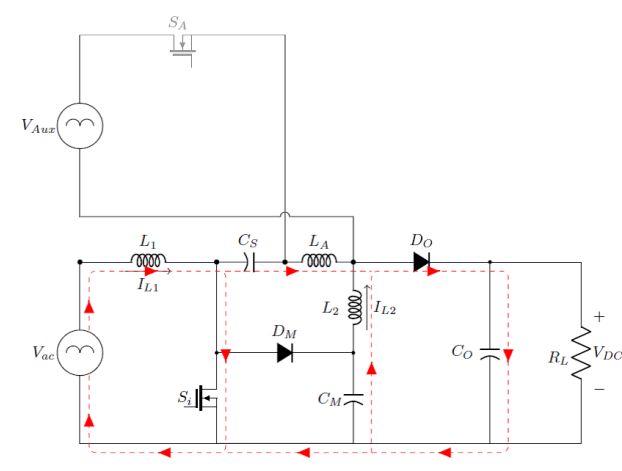

(c) Switching State $3\left[\mathrm{t}_{2}, \mathrm{t}_{3}\right]$

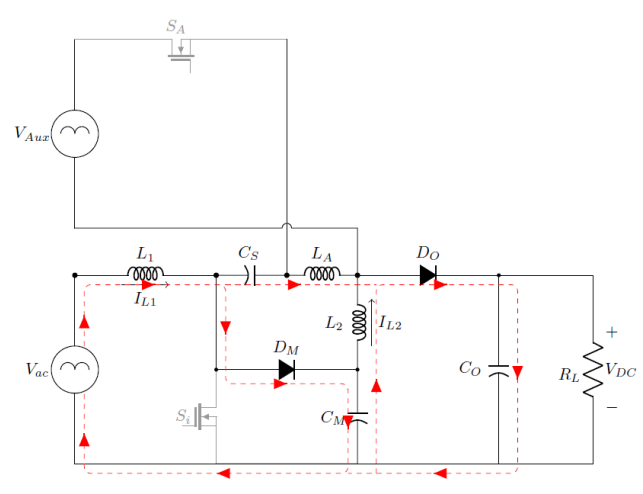

(b) Switching State $2\left[\mathrm{t}_{1}, \mathrm{t}_{2}\right]$

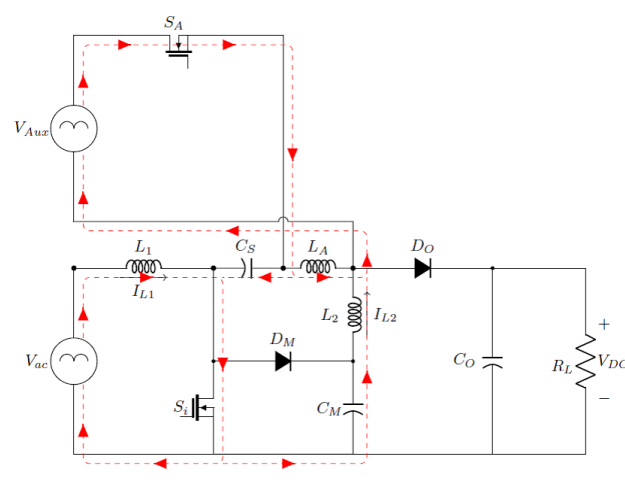

(d) Switching State $4\left[\mathrm{t}_{3}, \mathrm{t}_{4}\right]$

Figure 3. Equivalent Circuit of PFC Reconversion DIPSEPIC Converter

capacitor $C_{M}$ charges the inductor $L_{2}$ and capacitor $C_{M}$. As a result it increases the inductor current and capacitor voltage respectively.

Sequentially, the capacitors $C_{o}$ discharge and deliver their stored energy to load. Equivalent circuit of PFC reconversion DIPSEPIC converter in this state is shown in Figure 3(d).

\section{Design of Fuzzy Logic Controller}

In high-performance drive systems, the motor speed should strictly follow a specified reference trajectory regardless of any load disturbances, parameter variations, and model uncertainties; however, the controller design for such systems plays a crucial role in system performance. The decoupling characteristics of vector-controlled IM are adversely affected by the parameter changes in the motor (Zaky \& Metwaly, 2017). The motorcontrol issues are traditionally handled by fixedgain proportional-integral (PI) and proportionalintegral-derivative (PID) controllers. However, the fixed-gain controllers are very sensitive to parameter variations and load disturbances. In induction motor drives systems, FLC with
IFOC can be used as a speed controller, where the motor speed is compared with a reference speed and the resultant error is fed into FLC to produce the output control signal (Tarbosh et al., 2020). The design of all of the above controllers depends on the exact mathematical model of the system. However, it is often difficult to develop an accurate mathematical model of a system due to unknown load variation, and to unknown and unavoidable parameter variations due to saturation, temperature variations, and system disturbances (Fateh et al., 2017).

In order to overcome the above problems, the fuzzy-logic controller (FLC) is employed for motor control purposes (Farah et al., 2019). The mathematical tool for the FLC is the fuzzy set theory introduced by Zadeh (1965). In comparison with the conventional PI, PID, and their adaptive versions, the FLC has some advantages such as:

1. It does not need any exact mathematical model of a system;

2. It can handle nonlinearity of arbitrary complexity; and 
3. It is based on the linguistic rules with an IFTHEN general structure, which is the basis of human logic.

This section investigates the application of the Fuzzy IFOC SPIM Drive utilizing PFC Reconversion DIPSEPIC system.

The FLC-based IFOC for SPIM drives consists of five controls namely, Speed $\left(\omega_{r}\right)$, torque $\left(T_{e}\right)$, error current $\left(I_{d s 1}^{e r}, I_{q s 1}^{e r}\right)$ and flux $\left(\lambda_{r}\right)$. Each individual control is substituted by an individual FLC to enhance the system performance (Tir et al., 2016; Gerald et al., 2011). The fuzzybased IFOC model is presented in Figure 4. In this work, the error and change in error concerning time are taken as the input, and the output variable is regarded as the output reference value (Hannan et al., 2018).

\section{Fuzzification, Inference and Defuzzification}

$$
x_{\text {out }}(n)=\int_{\text {discrete }} \Delta x_{\text {out }}(n)=f\left(* \Delta e(n), \Delta x_{e}(n)\right)
$$

Equation for the change of error $\Delta e(n)$ is

$$
\Delta e(n)=\left(G_{1 x}^{*} x_{e}(n)\right)-\left(G_{2 x} * \Delta x_{e}(n-1)\right)
$$

Where $\Delta x_{e}(n-1)$ is error of past sample value, $\Delta x_{e}(n)$ is error of present sample value.

The gains $G_{1 x}$ and $G_{2 x}$ can be varied in order to tune the fuzzy controller so that it reaches the desired performance level. The output gain $G_{o}$ can also be tuned.

The equation for the sample of error $\Delta x_{e}(n)$ is $\Delta x_{e}(n)=x_{r}(n)-x_{m}(n)$

where $x_{a}(n)$ is the present sample of actual value, $x_{r}(n)$ is the present sample of reference value.

The input membership functions are given by $\mu_{\mathrm{x}_{\mathrm{j}}^{\mathrm{j}}} \Delta x_{e}(n-i), i=[01]$. The fuzzy set is $\mathrm{X}_{\mathrm{i}}^{\mathrm{j}}$, where $\mathrm{j}=(1$ to 7$)$. The linguistic values are $(-3)$, $(-2),(-1)$ as an indication of increasing negative values and (1),(2),(3) for positive incremental values and zero( 0 ) for neutral values.

The inference utilizes IF-THEN rules and present in the knowledge base to make decisions, where the Product operation is utilized for the premises and Min operation is used for the implication.

Product $\mu_{\mathrm{A}^{*} \mathrm{~A}^{\prime}}(\mathrm{a})=\mu_{\mathrm{A}}(\mathrm{a}) \mu_{\mathrm{A}^{\prime}}(\mathrm{a}), \mathrm{a} \mu$

$\operatorname{Min} \mu_{A^{*} A^{\prime}}(a)=\min \left\{\mu_{A}(a), \mu_{A^{\prime}}(a): a \varepsilon A\right\}$

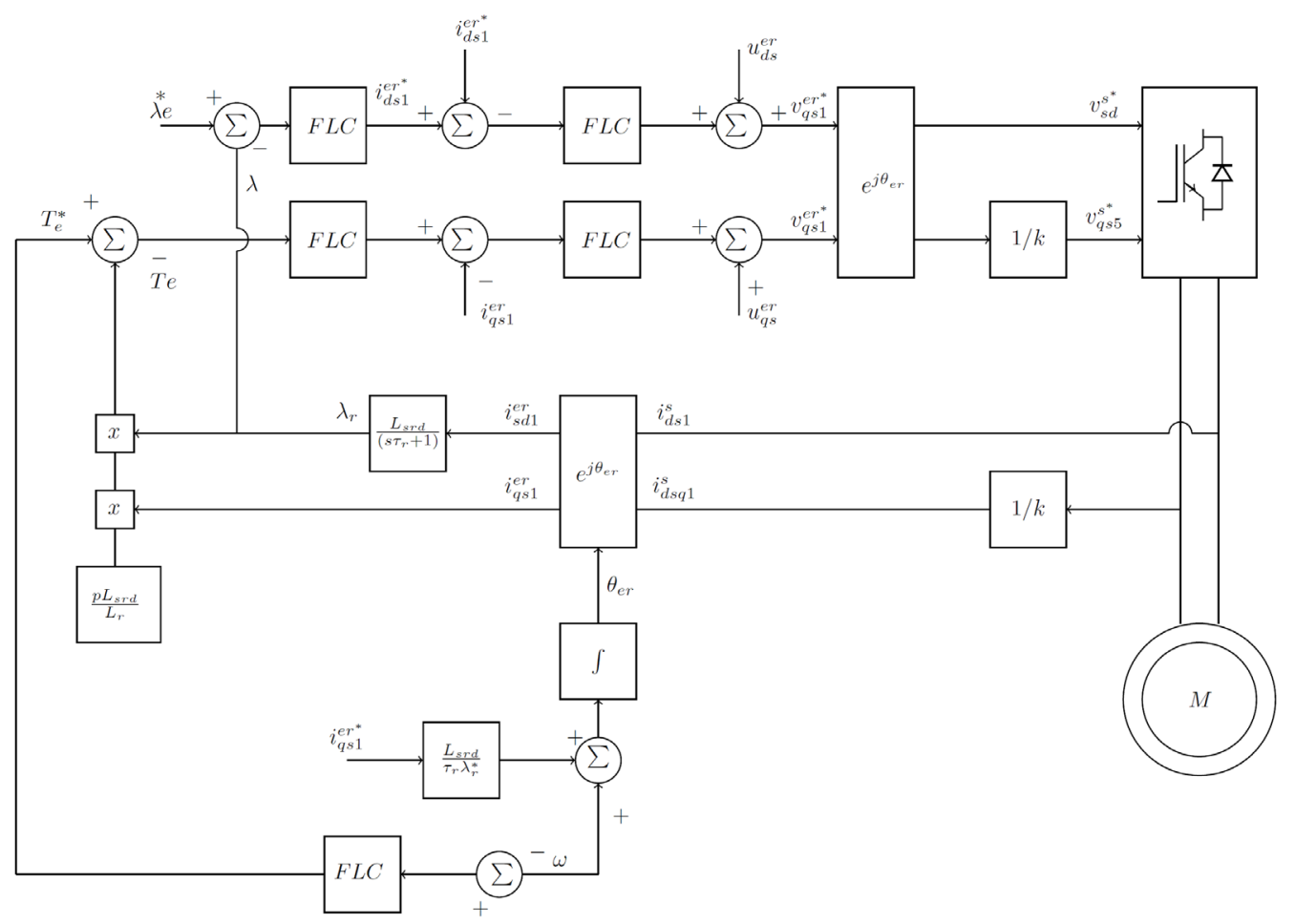

Figure 4. Fuzzy IFOC Speed Control Method for SPIM (drives) 
The output fuzzy set is $\widehat{U^{j}}$, with regard to the output membership functions $\mu_{\widehat{U^{j}}}(u)$. The defuzzification is achieved by centre of gravity method as defined by Equation (13). The governing equation of the inverter controller is given by Equation (14)

$$
\begin{gathered}
y=\frac{\sum_{j=1}^{R} c^{j} \int \mu_{\widehat{U^{j}}}(u) d u}{\sum_{j=1}^{R} \int \mu_{\widehat{U^{j}}}(u) d u} \\
x_{\text {out }}=x_{\text {out }}+G_{\text {Ox }} \Delta x_{\text {out }}
\end{gathered}
$$

Hence, the incremental $\Delta x_{\text {out }}$ command is the effective output of the FC.

\section{The Fuzzy Controller Rule Base}

The knowledge base is the biggest asset of the fuzzy controller. Table 1 shows the rule base of Fuzzy controller. Through the careful design of the knowledge base, the informal knowledge of the operation gets included in the fuzzy controller (Gdaim et al., 2015). Evenly dispersed triangular membership functions are utilized to simplify its digital realization. By varying the gains, the scaling can be incremented or reduced (Tarbosh et al., 2020). In this work, it is fixed to unity and is varied until the necessary response is obtained.

Table 1. Fuzzy Controller Rule Base

\begin{tabular}{|c|c|c|c|c|c|c|c|c|}
\hline \multicolumn{2}{|c|}{ Rule Base } & \multicolumn{7}{|c|}{ E2(e) } \\
\hline & $\mathrm{U}$ & -3 & -2 & -1 & 0 & 1 & 2 & 3 \\
\hline \multirow{6}{*}{ E1(e) } & -3 & 3 & 3 & 3 & 2 & 2 & 2 & 1 \\
\cline { 2 - 9 } & -2 & 3 & 3 & 2 & 2 & 2 & 0 & -3 \\
\cline { 2 - 9 } & -1 & 3 & 2 & 2 & 2 & 1 & -1 & -3 \\
\cline { 2 - 9 } & 0 & 3 & 2 & 1 & 0 & -1 & -2 & -3 \\
\cline { 2 - 9 } & 1 & 3 & 1 & -1 & -2 & -2 & -2 & -2 \\
\cline { 2 - 9 } & 2 & 3 & 0 & -2 & -2 & -2 & -3 & -3 \\
\cline { 2 - 9 } & 3 & -1 & -2 & -2 & -2 & -3 & -3 & -3 \\
\hline
\end{tabular}

The rule base is calculated so that, when the error signal or change in the error signal is huge there will be a considerable change in the current command to reveal the same. This command helps in manipulating the system competencies of the IFOC drive to the fullest extent. When the real value equals reference value, the error and change in error are said to be zero. For any other disturbances, the rules close to the midpoint rapidly adjust the current to sustain the original value in relation to the reference value.

\section{Design and Analysis}

\section{Selection of DIPSEPIC Converter Components}

The DIPSEPIC ensures efficient PFC converter for $\mathrm{AC}$ to $\mathrm{DC}$ conversion. The DIPSEPIC converter output voltage can be either higher or lower than the input peak voltage (Shi et al., 2016) which is employed for driving the SPIM auxiliary winding reconversion drive. The Design calculation of DIPSEPIC input inductor $L_{1}$, inner inductor $L_{2}, 4$-Series Capacitor $\left(C_{S}\right)$, Multiplier Capacitor $\left(C_{M}\right)$ and output DC filter capacitor $\left(C_{0}\right)$ is derived based on the following parameters namely desired input voltage $\left(V_{a c}\right)$, input current $\left(I_{a c}\right)$, output voltage $\left(V_{d c}\right)$, duty cycle (D), switching frequency $\left(f_{s}\right)$, auxiliary winding voltage $\left(V_{A u x}\right)$ and Auxiliary winding current $\left(I_{A u x}\right)$.

The input inductance can be defined by Equation (16) which is obtained from Equation (15). The input inductance is calculated for the power converter operating at the peak of the lowest input voltage. For this operation point, the instantaneous input voltage is equal to $V_{a c P}=141.4 \mathrm{~V}$, the converter duty cycle is equal to $\mathrm{D}=0.5$, and the input current ripple $\left(\Delta \mathrm{I}_{L 1}\right)$ considered is $23 \%$ of the peak input current $\left(I_{i P}\right)$. Therefore, the input current ripple is calculated as follows:

$\Delta \mathrm{I}_{L 1}=I_{a c P} \times 0.23=20 \times 0.23=4.6 \mathrm{~A}$

The input inductance calculated is equal to

$L_{1}=\frac{V_{a c p} D}{\ddot{\mathrm{A}} \mathrm{I}_{L 1} f_{s}}=\frac{141.4 \times 0.5}{4.6 \times 10000}=1536 \mu \mathrm{H}$

The $L_{1}$ inductor can be defined by Equation (17). The $L_{2}$ inductance utilized in the practical implementation is half of the $L_{1}$ inductance.

$L_{2}=L_{1} / 2=1536 / 2=768 \mu H$

The auxiliary winding inductor $L_{A}$ can be defined by Equation (19) obtained from Equation (18), where the auxiliary winding voltage $V_{A u x}=100 \mathrm{~V}$ and auxiliary winding current $I_{A u x}=10 \mathrm{~A}$.

$$
\begin{aligned}
& \Delta \mathrm{I}_{L A}=I_{A u x} \times 0.23=10 \times 0.23=2.3 \mathrm{~A} \\
& L_{A}=\frac{V_{A u x} D}{2 * \Delta \mathrm{I}_{L A} f_{s}}=\frac{100 \times 0.5}{2 * 2.3 \times 10000}=1086 \mu \mathrm{H}
\end{aligned}
$$


The average current of the inductor $L_{2}$ is equal to the output DC current $\left(I_{d c}\right)$, and its peak value shall be used in Equation (20). Considering an input voltage equal to $V_{i}=100 \mathrm{Vrms}$ and a maximum capacitor voltage ripple equal to $12 \%$ of the output voltage $\left(\Delta V_{c}=50 \mathrm{~V}\right)$, the capacitors $C_{S}$ and $C_{\mu}$ can be defined as.

$C_{s}=C_{M}=\frac{I_{L 2} D}{2 \Delta V_{c} f_{s}}=\frac{9.2 \times 0.5}{2 * 50 \times 10000}=4600 \mathrm{nF}$

The output capacitance $\left(C_{0}\right)$ can be defined by Equation (21), where output power $P_{0}=3 \mathrm{~kW}$, grid frequency $f_{g}=50 \mathrm{~Hz}$, output DC voltage ripple $\left(\Delta V_{D C}\right)$ is equal to $1 \%$ of the output voltage $V_{D C}=425 \mathrm{~V}$.

$C_{0}=\frac{P_{0}}{2 \pi f_{g} \times 2 V_{D C} \Delta V_{D C}}=\frac{3000}{2 \pi 50 \times 2 \times 425 \times 4.25}=2643 \mu F$

\section{Selection of Switching Devices}

The voltage and current rating of the switching devices are completely based on the power rating of SPIM. In order to choose the correct rating of the switching devices, the following modelling is performed. The rating of Single phase inverter is determined by the case when the connected load is at its maximum value, i.e., for $2 \mathrm{Hp} \mathrm{SPIM}$ at 0.7 power factor $(\mathrm{PF})$ due to high starting current load power is taken as 3000 watts. The inverter also supplies 1000 Watts active power to the auxiliary winding. So the inverter power is the sum of SPIM, and auxiliary winding active power assumed to be $4000 \mathrm{w}$.

$I_{i n v}=\frac{P_{R i n v}}{V_{i n v}}=\frac{4000 \mathrm{~W}}{230 \mathrm{~V}}=17.39 \mathrm{~A}$

$P_{i n v}=V_{i n v} \times I_{i n v} \times \cos \theta$

$P_{i n v}=230 \mathrm{~V} \times 17.39 \mathrm{~A} \times 0.75$

$P_{i n v}=2999.77 \mathrm{~W}$

Where $\left(V_{i n v}=400 \mathrm{~V}\right), \quad\left(I_{i n v}=17.39 \mathrm{~A}\right) \quad$ and $\left(P_{\text {Rinv }}=4000 \mathrm{~W}\right)$ indicate single-phase inverter voltage, current power and rated power respectively.

The reactive power of the motor is supplied by the single phase inverter. Hence, the reactive power flow through inverter $\left(Q_{i v v}\right)$ is equal to the reactive power demand of the load which is given by the following equations:

$$
Q_{i v v}=\frac{P_{i v v}}{\cos \theta} \times \sin \theta
$$

$$
\begin{aligned}
& Q_{i v v}=\frac{2999.77}{0.75} \times 0.66 \\
& Q_{i v v}=2645.54 \mathrm{VAR}
\end{aligned}
$$

Therefore the apparent power of inverter is calculated using equation,

$$
\begin{aligned}
& V A_{i n v}=\sqrt{P_{i n v}^{2}+Q_{i n v}^{2}} \\
& V A_{C T^{2} I}=\sqrt{(2999.77)^{2}+(2645.54)^{2}} \\
& V A_{i n v}=3999.69 \mathrm{VA}
\end{aligned}
$$

The maximum RMS current through the $1 \Phi$ inverter current is alternatively calculated from equations:

$I_{i n v}=\frac{V A_{i n v}}{V_{i n v}}$

$I_{i n v}=\frac{3999.69 \mathrm{VA}}{230 \mathrm{~V}}$

$I_{i n v}=17.39 \mathrm{~A}$

The maximum current through the switching devices $\left(I_{i n v s w}\right)$ of the single phase inverter is given by the equation,

$$
\begin{aligned}
& I_{i n v_{-} s w}=\text { safety margin }\left\{I_{i n v_{-} p k}+I_{i n v_{-} r i p}\right\} \\
& I_{i n v_{-} s w}=1.25\{24.58+1.229\} \\
& I_{i n v_{-} s w}=32.26 \mathrm{~A}
\end{aligned}
$$

Where peak line current passes through the single phase inverter $\left(I_{i n v_{\text {_peak }}}=\sqrt{2} \times 17.39 \mathrm{~A}\right)$, the peakto-peak ripple current in the proposed inverter, is considered to be $5 \%$ of the peak line current and is calculated as $1.229 \mathrm{~A}$, and safety margin for design purposes is taken as 1.25.

The maximum voltage through the switching devices $\left(V_{i n v s w}\right)$ in the single phase inverter is given by equations (38) and (39), the maximum voltage through the switching devices mainly depends on DC-link voltage $\left(V_{d c}\right)$ and the modulation index $(M)$.

$$
\begin{aligned}
& V_{d c}>\left\{2 \times \sqrt{\frac{2}{3}} \times V_{i n v_{r m s}}\right\} M \\
& V_{d c}>\left\{2 \times \sqrt{\frac{2}{3}} \times 230 \mathrm{~V}\right\} 0.8 \\
& V_{d c}>300 \mathrm{~V} \\
& V_{d c}=\operatorname{safety} \text { margin } \times V_{d c} V_{d c}=1.25 \times 325 \mathrm{~V} \\
& V_{d c}=406.25 \mathrm{~V}
\end{aligned}
$$


Table 2. Components and Specifications

\begin{tabular}{|c|l|c|}
\hline S. No & \multicolumn{1}{|c|}{ Component Details } & Operating values \\
\hline 1 & Transformer 230V/100V,50 Hz & $2000 \mathrm{VA}$ \\
\hline 2 & $\begin{array}{l}\text { DIPSEPIC inductor }\left(\mathrm{L}_{1}, \mathrm{~L}_{2}, \mathrm{~L}_{3}\right) \\
\text { Core type: "Round" Size : T45*26*15 ring Toroidal ferrite core Copper gauge : “22”" }\end{array}$ & $\begin{array}{c}1.5 \mathrm{mH}, 0.75 \mathrm{mH}, 1 \\
\mathrm{mH}\end{array}$ \\
\hline 3 & $\begin{array}{l}\text { DIPSEPIC Capacitors }\left(\mathrm{C}_{\mathrm{s}} \text { and } \mathrm{C}_{\mathrm{M}}\right) \\
\text { Type: DIP, Aluminum Electrolytic Capacitor }\end{array}$ & $5 \mu \mathrm{F} / 450 \mathrm{~V}$ \\
\hline 4 & $\begin{array}{l}\text { DC link filter Capacitors } \\
\text { Type: DIP, Aluminum Electrolytic Capacitor }\end{array}$ & $2600 \mu \mathrm{F} / 450 \mathrm{~V}$ \\
\hline 5 & $\left(\mathrm{D}_{0}\right.$ and $\left.\mathrm{D}_{\mathrm{M}}\right)$ - Totally two Power Diodes for proposed DIPSEPIC -10A04 & $400 \mathrm{~V}, 10 \mathrm{~A}$ \\
\hline 6 & $\begin{array}{l}\text { Diode Bridge Rectifier for Main Supply and Auxiliary Winding Reconversion - } \\
\text { KBPC2010) }\end{array}$ & $1000 \mathrm{~V}, 20 \mathrm{~A}$ \\
\hline 7 & $\begin{array}{l}\left(\mathrm{S}_{1}-\mathrm{S}_{\mathrm{a}}\right),\left(\mathrm{S}_{1}-\mathrm{S}_{4}\right)-\text { Twelve N-Channel Power IGBTs for DIPSEPIC and Single-phase } \\
\text { inverter - FGB20N60SF }\end{array}$ & $600 \mathrm{~V}, 20 \mathrm{~A}$ \\
\hline 8 & dSPACE Processor board- TMS320F240 & DSPs \\
\hline DSPs & Voltage Transducer - Part number: LEM LV 25-P & $10-500 \mathrm{~V} / 10 \mathrm{~mA}$ \\
\hline 10 & Current transducer - Part number: HXS 10-NP/SP3 & $10-20 \mathrm{~A}$ \\
\hline 11 & Single Phase Induction Motor & $2 \mathrm{Hp}, 230 \mathrm{~V} / 50 \mathrm{~Hz}$ \\
\hline
\end{tabular}

Here $\left(V_{d c}\right)$ denotes DC-link voltage which must be higher than the peak value of the line voltage (line voltage value is $325 \mathrm{~V}$ ). The maximum voltage across the device shall be $406.25 \mathrm{~V}$, and the current capability of the device is $32.26 \mathrm{~A}$. The closest commercial rating for switching device insulated gate bipolar transistor (IGBT) is chosen as $600 \mathrm{~V}$ which is higher than that of $406.25 \mathrm{~V}$ and $40 \mathrm{~A}$ for the aforementioned value of $32.26 \mathrm{~A}$. Therefore, the rating of the switching devices (IGBTs) of the inverter points to the values of $600 \mathrm{~V}$ and $40 \mathrm{~A}$.

The details of the different parameters and the related specifications are given in Table 2.

\section{Simulation Analysis}

\section{Performance Validation under Steady State Condition}

In order to evaluate the performance of the proposed DIPSEPIC converter, a $2 \mathrm{Hp}$ induction motor fed by a voltage source inverter (VSI) with power factor correction, auxiliary winding feedback reconvention DIPSEPIC converter is considered. The focus of this work is to analyze the behavior of the motor power factor and motor efficiency by utilizing the auxiliary winding power. The conventional scheme of Without Reconversion Auxiliary Boost (WORAB) converter provides/enables an improved power factor and high converter efficiency in $\mathrm{AC}$-side using PFC DIPSEPIC system.

The response of the system is shown in Figure 5.
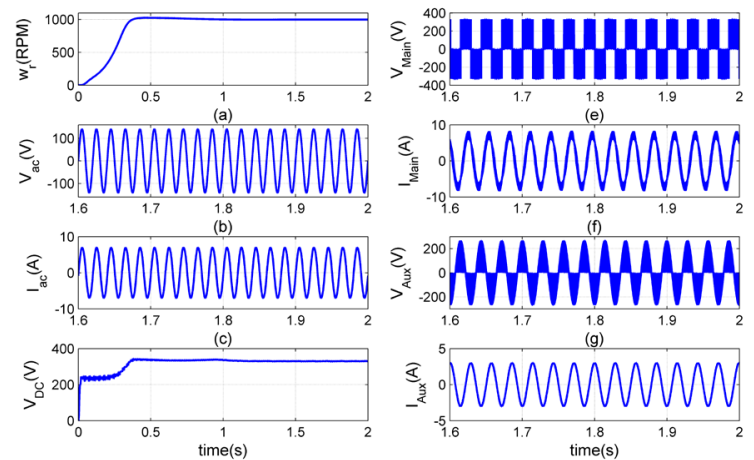

Figure 5. Simulation Results of SPIM with PFC Reconversion DIPSEPIC (a) Motor speed (b) Input AC Voltage (c) Input AC Current (d) DC-link Voltage (e) SPIM Main Winding Voltage (f) SPIM Main Winding Current (g) SPIM Auxiliary Winding Voltage (h) SPIM Auxiliary Winding Current

Figure 6 shows simulation comparison of power waveform of WORAB and WRAB. Analyzing the waveforms of without reconversion auxiliary boost (WORAB) converter as simulation results at a set speed of $w_{r}=1000 \mathrm{rpm}$, the Torque $T_{e}=3 \mathrm{Nm}$, mechanical output power $P_{\text {mech }}=313.5 \mathrm{~W}$, main winding real power $P_{\text {Main }}=510 \mathrm{~W}$, main winding reactive power $P_{\text {Rmain }}=595 \mathrm{~W}$, auxiliary winding real and reactive powers are approximately zero at rated set speed, ac input real power $P_{a c}=540 \mathrm{~W}$, and the reactive power $P_{R a c}=88 \mathrm{~W}$. The Motor 
Efficiency is calculated as $61.47 \%$ and Motor power factor is $P F_{M}=0.65$. The overall system efficiency obtained is $58.05 \%$ and power factor $P F=0.986$.
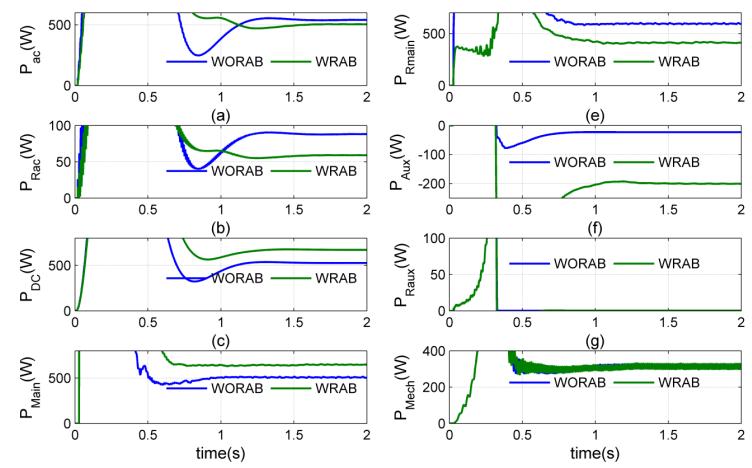

Figure 6. Simulation Results of SPIM with PFC Reconversion DIPSEPIC (a) Motor speed (b) Input AC Voltage (c) Input AC Current (d) DC-link Voltage (e) SPIM Main Winding Voltage (f) SPIM Main Winding Current (g) SPIM Auxiliary Winding Voltage (h) SPIM Auxiliary Winding Current

On analyzing the simulation waveforms of with reconversion auxiliary boost (WRAB) converter at a set speed of $w_{r}=1000 \mathrm{rpm}$, Torque $T_{e}=3 \mathrm{Nm}$, mechanical output power $P_{\text {mech }}=353.5 \mathrm{~W}$, main winding real power $P_{\text {Main }}=648 \mathrm{~W}$, main winding reactive power $P_{\text {Rmain }}=410 \mathrm{~W}$, Auxiliary winding real power $P_{A u x}=-200 \mathrm{~W}$ and reactive power approximately zero. ac input real power $P_{a c}=505 \mathrm{~W}$ and the Reactive Power $P_{\text {Rac }}=55 \mathrm{~W}$. The motor efficiency is calculated as $69.97 \%$ and Motor Power factor is $P F_{M}=0.845$. The overall system efficiency obtained is $62.07 \%$ and power factor $P F=0.993$.

The comparative analysis of conventional scheme (without reconversion auxiliary boost converter) and proposed scheme (with reconversion auxiliary boost converter) shows that input power of the proposed WRAB scheme is reduced by utilizing the auxiliary power which is fed back to the motor input. As a result an enhanced efficiency and an increase in power factor of both system and the motor is achieved.

\section{Performance Validation under Transient Conditions}

The performance of the proposed approach is validated by testing under different operating conditions and parameter variations. Simulation tests are carried out on an inverter-duty SPIM. It can be noticed that the performance of the second-order model is quite satisfying with a rapid response. The capability of the Fuzzy Logic Controller (FLC) to avoid load distortions is simulated for two conditions at different reference speeds and also for continuous reference speed with variable load (Zeb et al., 2017). For the different speed conditions, the beginning speed of $800 \mathrm{rpm}$ the effect of using a step increment for the speed of $1200 \mathrm{rpm}$ at $2 \mathrm{~s}$, and then decreasing the speed to $1000 \mathrm{rpm}$ at $4 \mathrm{~s}$ were analyzed. The simulated responses (rotor speed and torque current component) of the Fuzzy and PI controlled drives are illustrated in Figure 7 and Figure 8.

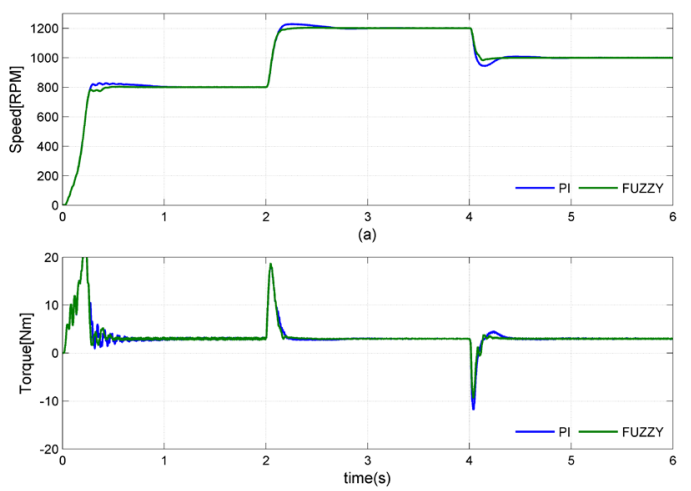

Figure 7. Transient Response of SPIM for change in Speed at Constant Load Torque

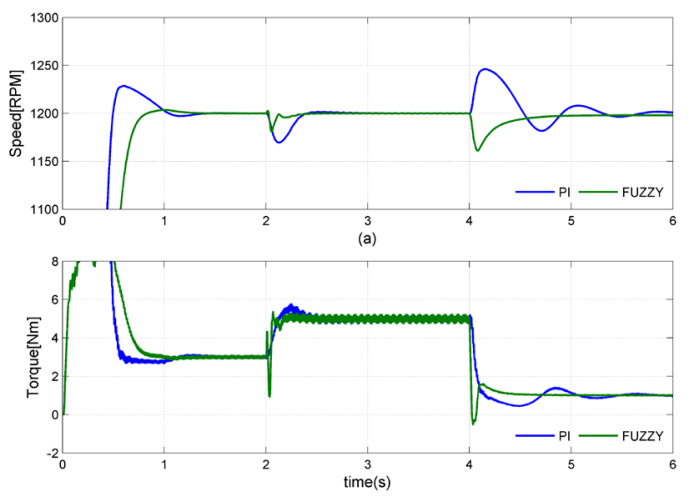

Figure 8 . Transient Response of SPIM for change in Load Torque at Speed of $1200 \mathrm{rpm}$

When comparing the performance of Fuzzy and PI controller, it can be noticed that the fuzzy drive provides considerable improvements in comparison with the fixed-parameter PI system. The fuzzy drive provides a quicker response with a lower overshoot/ undershoot. At the initial reference speed of 800 rpm, fuzzy drive exhibits a lower settling time $(0.5 \mathrm{~s})$ with lower overshoot/undershoot $( \pm 9 \mathrm{rpm})$ in comparison to the PI controller with a settling time of $0.9 \mathrm{~s}$ and an overshoot/undershoot of \pm 20 $\mathrm{rpm}$. When the increase in speed varies from 800 
rpm to $1200 \mathrm{rpm}$ at $2 \mathrm{~s}$, fuzzy drive has a settling time of $0.2 \mathrm{~s}$ without any overshoot/undershoot and PI controller has a higher settling time $0.85 \mathrm{~s}$ with an overshoot/undershoot of $\pm 40 \mathrm{rpm}$. When the control speed is decreased to $1000 \mathrm{rpm}$, the fuzzy drive gets a settling time of $0.25 \mathrm{~s}$ with overshoot/ undershoot of $\pm 4 \mathrm{rpm}$ and PI controller has higher settling time of $0.6 \mathrm{~s}$ with an overshoot/undershoot of $\pm 53 \mathrm{rpm}$.

\section{Experimental Verification}

The hardware design is experimentally validated to substantiate the feasibility and achievability of the proposed method. The experimental block diagram of Fuzzy IFOC SPIM Drive utilizing PFC Reconversion DIPSEPIC system presented (Figure 9) is employed for driving the SPIM with improved power factor and high efficiency. It primarily comprises the DIPSEPIC Converter-fed PFC AC-DC drive with active power utilization from auxiliary winding in the front end, single-phase inverter in the middleend and SPIM. A digital signal processor (DSP) TMS320F240 is used for the development of the proposed PFC Reconversion DIPSEPIC system with Fuzzy IFOC SPIM Drive. Opto-isolation is provided between the DSP and the gate driver of the step-up converter and five-level inverter switches using 4N35 optocouplers. The necessary protection and scaling circuits are developed for scaling the output of the voltage sensor in order to make it compatible with the analogue-todigital converter of the DSP. The main functions of the PFC Reconversion DIPSEPIC are to convert AC to DC with power factor correction, and to convert auxiliary winding active power to DC-link power and inject it into the singlephase inverter of SPIM drive. The converter and inverter switches operate at $10 \mathrm{kHz}$. The control signals are provided by the DSP processor. The input power is acquired from a $230 \mathrm{~V} / 50 \mathrm{~Hz}$ AC source. The PFC reconversion DIPSEPIC is connected to the auxiliary winding of SPIM through a diode bridge rectifier and to the main winding through a single-phase inverter.

\section{Test Condition: Load Torque: 3.45 Nm; Speed: $1000 \mathrm{rpm}$}

Figure 10 shows the waveform of filtered AC current $4.8 \mathrm{~A}$; voltage $101 \mathrm{~V}$.

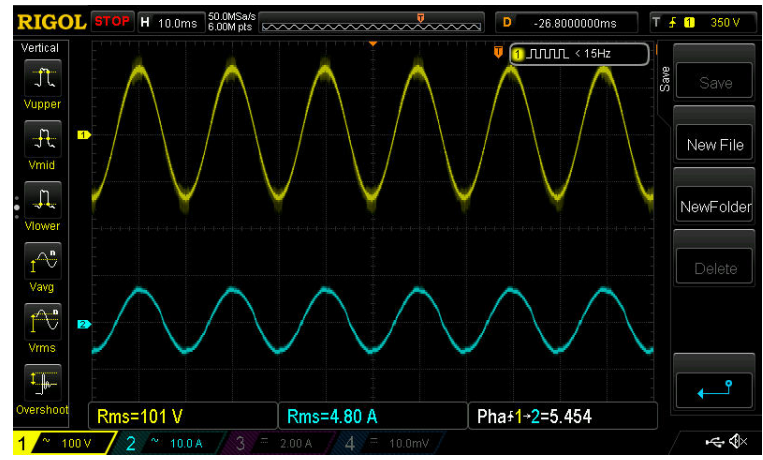

Figure 10. Hardware Output - AC Voltage: $101 \mathrm{~V}$ and Current: $4.8 \mathrm{~A}$

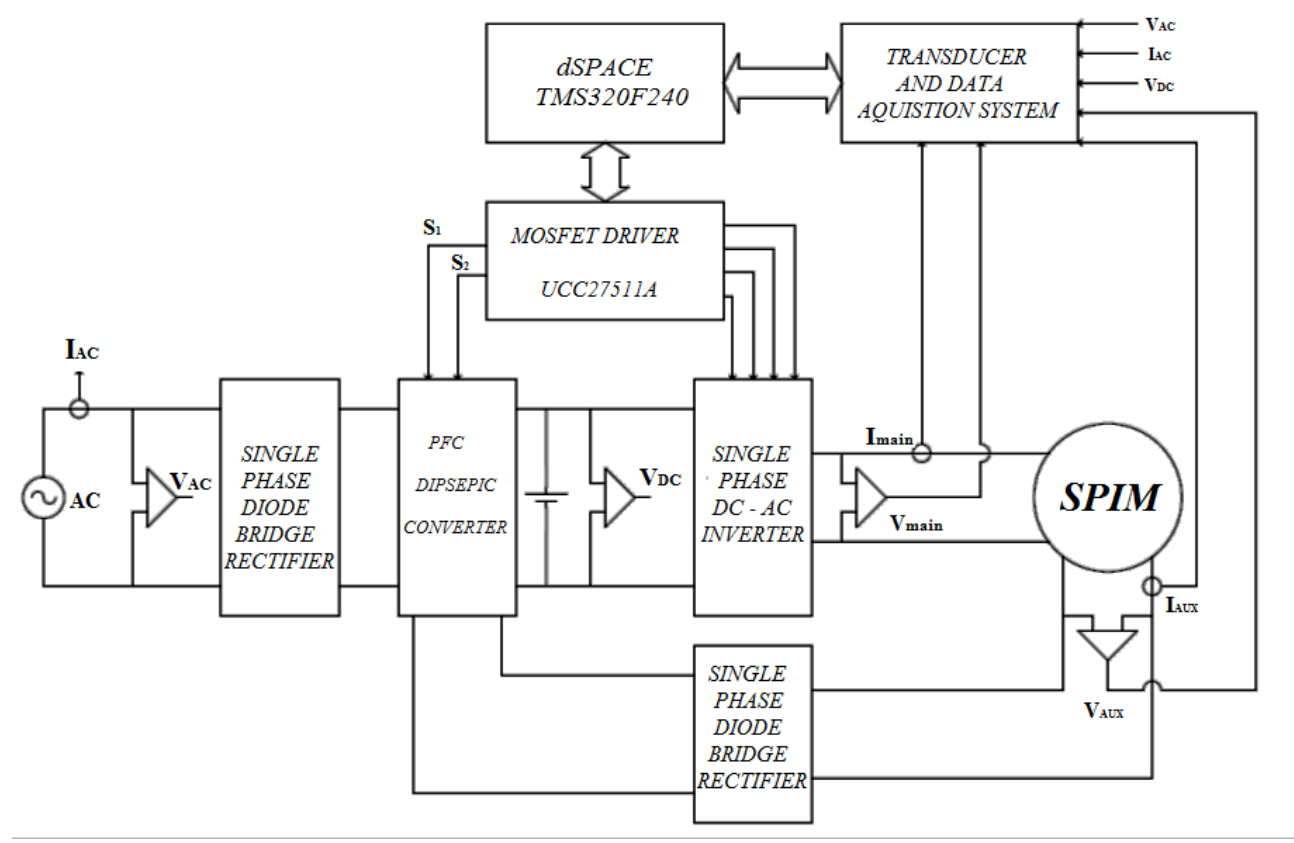

Figure 9. Block Diagram of Experimental Test Setup 
The power factor of the system is shown to be 0.995. In Figure 11 waveform showing DC bus voltage: $330 \mathrm{~V}$, DC bus current: $2.09 \mathrm{~A}$.

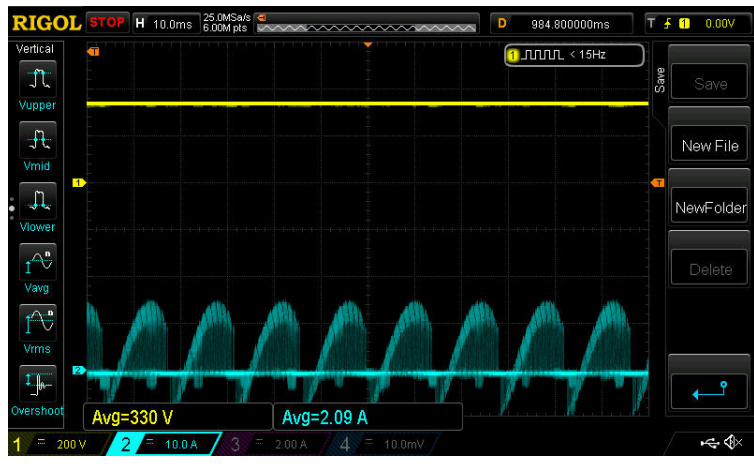

Figure 11. Hardware Output - DC bus Voltage: 330 V and Current: $2.09 \mathrm{~A}$

Figure 12 shows the main winding voltage to be $190 \mathrm{~V}$, main winding current to be $3.56 \mathrm{~A}$.

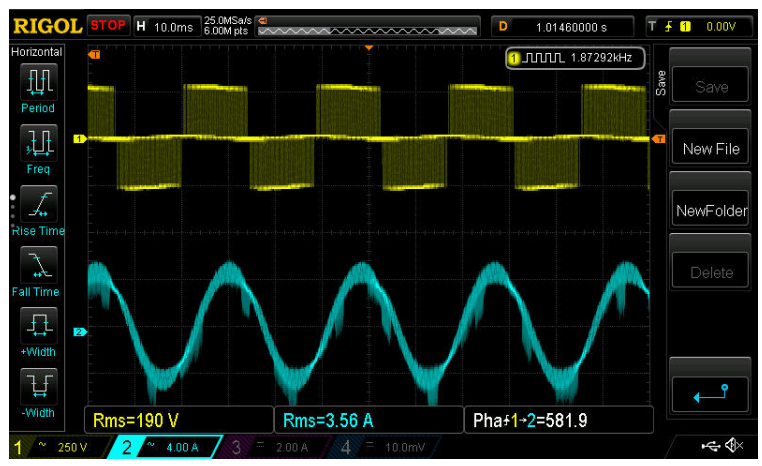

Figure 12. Hardware Output - Main Winding Voltage: $190 \mathrm{~V}$ and Current: $3.56 \mathrm{~A}$

Figure 13 shows the auxiliary winding voltage to $156 \mathrm{~V}$ and auxiliary winding current to be $1.5 \mathrm{~A}$.

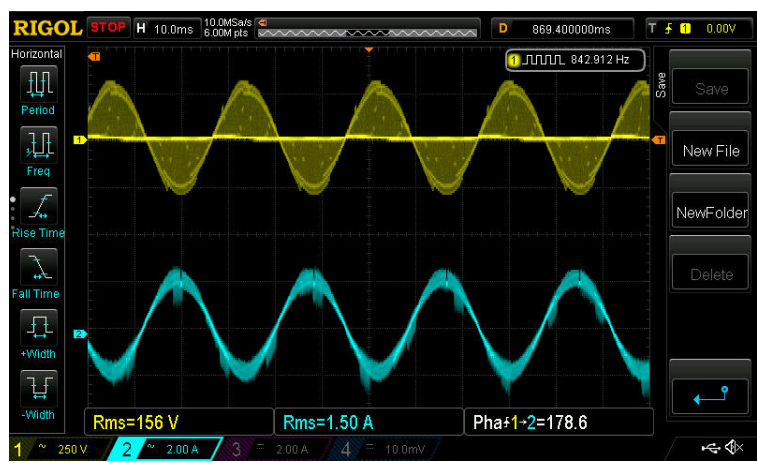

Figure 13. Hardware Output - Auxiliary Winding Voltage: $156 \mathrm{~V}$ and Current: $1.5 \mathrm{~A}$

As inferred from the waveforms obtained, output mechanical power of the motor: $361 \mathrm{~W}$; main winding power: $676.4 \mathrm{~W}$; Input DC bus power: 689.7 W; output auxiliary winding power: $234 \mathrm{~W}$ (which is $65 \%$ of output mechanical power).

Calculated values of efficiency:

- $\quad$ SPIM efficiency: $81.06 \%$;

- $\quad$ Inverter efficiency calculated: 98.07\%;

- Converter efficiency: 95.95\%;

- $\quad$ Overall system efficiency $74.46 \%$.

\section{Results and Discussion}

Figures 10 to 13 show the waveforms of voltage and current of the motor operating at the customary speed of $1000 \mathrm{rpm}$. Figure 14 shows the Fast Fourier transform (FFT) based harmonic analysis of the input current. It is indisputable on the basis of the FFT waveform that the input AC contains an acceptable level of harmonic content. The harmonic content for the input current is computed up to the 11 th harmonic.

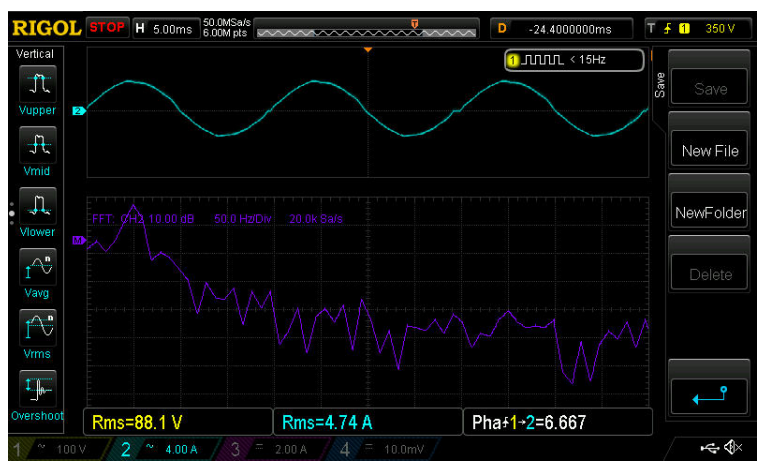

Figure 14. Hardware Output - AC Current FFT Analysis

Table 3 summarises the results achieved for the $2 \mathrm{Hp}$ SPIM of the same rating. Column (1) includes the results obtained though the conventional load test. Columns (2) and (3) comprise the simulation results obtained for the SPIM with reconversion auxiliary boost converter and without auxiliary boost converter. Column (4) includes the results obtained from the implemented hardware of PFC DIPSEPIC SPIM drive using IFOC. From the results it is obvious that the power factor of the motor, motor efficiency, overall system (PFC DIPSEPIC with SPIM) power factor, and practical efficiency have improved remarkably. 
Table 3. A Comparison of Results for a $2 \mathrm{Hp} \mathrm{SPIM}$

\begin{tabular}{|c|c|c|c|c|}
\hline \multirow{2}{*}{ Parameters (0) } & SPIM (Load Test) (1) & \multicolumn{2}{|c|}{$\begin{array}{c}\text { Simulation Results of SPIM } \\
\text { PFC DISEPIC }\end{array}$} & $\begin{array}{c}\text { PFC DISEPIC SPIM drive } \\
\text { (Hardware Result) (4) }\end{array}$ \\
\cline { 2 - 4 } & 3.18 & WORAB (2) & WRAB (3) & 3.45 \\
\hline Torque In Nm & 1420 & 1000 & 1000 & 1000 \\
\hline Speed in rpm & 483.87 & 313.5 & 353.5 & 361 \\
\hline $\begin{array}{c}\text { Output Mechanical } \\
\text { power in Watts }\end{array}$ & 0.691 & 0.651 & 0.84 & 0.744 \\
\hline Motor P.F & 62.9 & 61.47 & 69.9 & 81.06 \\
\hline Motor efficiency & NA & 0.986 & 0.99 & 0.995 \\
\hline Overall System P.F & NA & 58.05 & 62 & 74.46 \\
\hline $\begin{array}{c}\text { Overall System } \\
\text { Efficiency }\end{array}$ & & & 3 & \multirow{2}{*}{} \\
\hline
\end{tabular}

\section{Conclusion and Future Scope}

This paper presented a new power factor improvement scheme for SPIM using PFC reconversion DIPSEPIC. Although the proposed structure features a higher circuit complexity than the Modified SEPIC converter, the advantages obtained are the higher static gain for the operation with the lower input voltage range. The DIPSEPIC guaranteed an efficient PFC converter for $\mathrm{AC}$ to DC conversion, and it is also utilized for boosting the output voltage $\sqrt{ } 2$ times higher than the grid voltage from the $\mathrm{AC}$ main. The design of suitable capacitors, inductor, switching devices and other assorted parameters of PFC reconversion DIPSEPIC compatible with stable operation of SPIM is deduced. In addition to power factor improvement, Fuzzy IFOC speed control is also implemented. The performance analysis is carried out through a series of model simulations and experimental tests, and it has acknowledged that the proposed scheme with PFC has shown high motor performance such as almost unity power factor and an efficiency of $81.06 \%$. The overall system (PFC DIPSEPIC with SPIM) power factor obtained is 0.995 , and the efficiency obtained is $74.46 \%$. The results achieved showed a significant improvement with regard to the SPIM power factor, motor efficiency and overall system power factor and functional efficiency. The simulation results of the test carried out under steady-state and transient state conditions highlighted the speed tracking and disturbance rejection abilities of the Fuzzy IFOC speed control. This speed control makes the approach attractive for a wide range of industrial drive applications as it enables noteworthy energy conservation.

The future scope of research can be extended through a customized design of turns in the auxiliary winding of SPIM with a variable capacitive load connected across it. This capacitance will enable one to increase the starting torque, running torque, improved power factor and overall performance. Further, a closed-loop bidirectional control governed by Fuzzy logic control can be enhanced in order to achieve automatic power factor correction and regulate energy conversion.

\section{REFERENCES}

Collins, E. R., Puttgen, H. B. \& Sayle, W. E. (1988). Single-phase induction motor adjustable speed drive: direct phase angle control of the auxiliary winding supply. In Conference Record of the 1988 IEEE Industry Applications Society Annual Meeting (pp. 246-252).

Da Silva, C.A., Bidaud, F., Herbet, P. \& Cardoso, J. R. (2010). Power Factor Calculation by the Finite Element Method, IEEE Transactions on Magnetics, 46(8), 3002-3005.
Errouissi, R., Al-Durra, A. \& Muyeen, S. M. (2018). Experimental validation of a novel PI speed controller for $\mathrm{AC}$ motor drives with improved transient performances, IEEE Transactions on Control Systems Technology, 26(4), 1414-1421.

Farah, N., Talib, M. H. N., Shah, N. S. M., Abdullah, Q., Ibrahim, Z., Lazi, J. M. \& Jidin, A. (2019). A novel self-tuning fuzzy logic controller based induction motor drive system: An experimental approach, IEEE Access, 7, 68172-68184. 
Fateh, M. \& Abdellatif, R. (2017). Comparative study of integral and classical backstepping controllers in IFOC of induction motor fed by voltage source inverter, International Journal of Hydrogen Energy, 42(28), 17953-17964.

Gdaim, S., Mtibaa, A. \& Mimouni, M. F. (2015). Design and Experimental Implementation of DTC of an Induction Machine Based on Fuzzy Logic Control on FPGA, IEEE Transactions on Fuzzy Systems, 23(3), 644-655.

Gerald Christopher Raj, I. Soundar Rajan, P., Arul Prasanna, M. \& Renuga, S. (2011). State Space Modelling and Simulation of CSI Fed Induction Motor Drive System with a Simplified Program, Journal of Theoretical and Applied Information Technology, 27(2), 91-98.

Gnanavadivel, J., Yogalakshmi, P, Y., Natarajan, S. K. \& Krishna Veni, K. S. (2019). Design and development of single phase AC-DC discontinuous conduction mode modified bridgeless positive output Luo converter for power quality improvement, IET Power Electronics, 12(11), 2722 - 2730.

Hannan, M. A., Ali, J. A., Mohamed, A., Amirulddin, U. A. U., Tan, N. M. L. \& Uddin, M. N. (2018). Quantum-Behaved Lightning Search Algorithm to Improve Indirect Field-Oriented Fuzzy-PI Control for IM Drive, IEEE Transactions on Industry Applications, 54(4), 3793-3805.

Jannati, M., Anbaran, S. A., Asgari, S. H., Goh, W. Y., Monadi,A., Aziz, M. J. A. \& Idris, N. R. N. (2017). A review on Variable Speed Control techniques for efficient control of Single-Phase Induction Motors: Evolution, classification, comparison, Renewable and Sustainable Energy Reviews, 75, 1306-1319.

Kim, H. J., Seo, G. S., Cho, B. H. \& Choi, H. (2015). A Simple Average Current Control with OnTime Doubler for Multiphase CCM PFC Converter, IEEE Transactions on Power Electronics, 30(3), 1683-1693.

Mehta, C. P. \& Balamurugan, P. (2016). Buck-boost converter as power factor correction controller for plug-in electric vehicles and battery charging application. In IEEE 6th International Conference on Power Systems (pp. 1-6).

Mishra, A., Khan, U. \& Kazi, F. (2016). Power Factor Compensation (Reducing Electricity Bill), International Journal for Scientific Research and Development, 3(12), 845-849.

Munuswamy, R., Govindarajan, U. \& Anbukumar, K. (2019). Performance comparison and stability analysis of ACM and ENLC controlled SEPIC PFC converter, IET Power Electronics, 13(5), 991-1001.

Muteba, M \& Nicolae, D. V (2017). Effect of capacitive auxiliary winding on a three-phase induction motor performance behavior. In IEEE AFRICON Conference (pp.1384-1389).

Peuteman, J. \& Van Heerswynghels, G. (2010). Active power reversal in the main winding of a single phase induction motor. In the 5th IET International Conference on Power Electronics, Machines and Drive (pp. 1-6).

Senthil Kumar, S., Subbiah, M., \& Kumaresan, N. (2015). Analysis and control of capacitor-excited induction generators connected to a micro-grid through power electronic converters, IET Generation, Transmission \& Distribution, 9(10), 911-920.

Sessa, V, Iannelli, L \& Vasca, F, A. (2014). Complementarity model for closed-loop power converters, IEEE Transactions on Power Electronics, 29(12), 6821-6835.

Shi, C., Khaligh, A. \& Wang, H. (2016). Interleaved SEPIC Power Factor Preregulator Using Coupled Inductors In Discontinuous Conduction Mode With Wide Output Voltage, IEEE Transactions on Industry Applications, 52(4), 3461-3471.

Tamrakar, I. \& Malik, O. P. (1999). Power factor correction of induction motors using PWM inverter fed auxiliary stator winding, IEEE Transactions on Energy Conversion, 14(3), 426-432.

Tarbosh, Q. A, Aydoğdu, Ö., Farah, N., Talib, M. H. N., Salh, A. \& Çankaya, N. (2020). Review and Investigation of Simplified Rules Fuzzy Logic Speed Controller of High Performance Induction Motor Drives, IEEE Access, 8(493), 77-94.

Tir, Z., Malik, O. P. \& Eltamaly, A. M. (2016). Fuzzy logic based speed control of indirect field oriented controlled Double Star Induction Motors connected in parallel to a single six-phase inverter supply, Electric Power Systems Research, 134, 126-133.

Zadeh, L. A. (1965). Fuzzy sets, Information and control, 8(3), 338-353.

Zaky, M. S. \& Metwaly, M. K. (2017). A Performance Investigation of a Four-Switch Three-Phase InverterFed IM Drives at Low Speeds Using Fuzzy Logic and PI Controllers, IEEE Transactions on Power Electronics, 32(5), 3741-3753.

Zeb, K. Z., Saleem, A. K. \& Javed, W. U. M. A. (2017). Indirect field-oriented control of induction motor drive based on adaptive fuzzy logic controller, Electrical Engineering, 99(3), 803-815.

Zhao, X. \& Niu, S. (2017). Investigation of a New Hybrid Excitation Machine with Auxiliary Winding for Energy Recycling, IEEE Transactions on Magnetics, 53(11), 1-5.

https://www.sic.ici.ro 